\title{
AS POLÍTICAS DE PREVIDÊNCIA SOCIAL SOB A ÓTICA DO MODELO INCREMENTAL
}

SILVA, Raquel Andrade ${ }^{1}$

TEIXEIRA, Elaine Aparecida ${ }^{1}$

COSTA, Thiago de Melo Teixeira da ${ }^{1}$

RESUMO: Este artigo teve como objetivo analisar o incrementalismo das reformas das Políticas Públicas Previdência Social no Brasil desde 1988, inclusive a importante proposta de reforma pautada pelo Ex-Ministro Henrique Meirelles no governo do Presidente Michel Temer, que até 2018 estava tramitando no Congresso Nacional. Para tanto, foi necessário entender o contexto de formação da previdência social e os modelos de formulação de políticas públicas existentes, especialmente o modelo incremental. Realizou-se uma pesquisa qualitativa por meio da análise de conteúdo categorial fechada. Nesse sentido, os resultados encontrados elucidam os traços incrementais das leis previdenciárias no intuito de sanar problemas imediatos, perpetuando políticas de outros governos, especialmente a questão do déficit previdenciário.

Palavras-Chave: Previdência Social. Formulação de Políticas Públicas. Incrementalismo.

SUMMARY: This article had as objective to analyze the incrementalism of the reforms of Public Social Security Policies in Brazil since 1988, including the important proposal of reform ruled by the Former Minister Henrique Meirelles in the government of President Michel Temer, who until 2018 was working in the National Congress. To do so, it was necessary to understand the context of formation of social security and the models of formulation of existing public policies, especially the incremental model. A qualitative research was carried out through the analysis of closed categorial content. In this sense, the results found elucidate the incremental features of the social security laws in order to solve immediate problems, perpetuating policies of other governments, especially the issue of social security deficits.

Keywords: Social Security. Formulation of Public Policies. Incrementalism

\section{INTRODUÇÃO}

Em primeira análise, o termo "Políticas Públicas" possui diferentes definições. Nesse artigo, partese do entendimento de que ela é uma diretriz para enfrentar um problema público, podendo ser concretizada por programas, projetos, leis e outros. Assim, dentro do contexto do ciclo de políticas públicas encontra-se a formulação de políticas públicas que, segundo Sidney (2007), refere-se a um processo de produzir alternativas políticas capazes de solucionar um problema público.

A Previdência Social é uma política pública de subsistência garantida pela Constituição de 1988, que visa acobertar os seus beneficiários em caso de perda da capacidade laborativa, ocasionada pela idade avançada ou por outros riscos sociais, tais como doenças, acidentes de trabalho, reclusão, desde que efetuada a contribuição para o custeio do sistema (ZANIRATO, 2009).

Nesse sentido, é salutar compreender a formulação da Política Pública de Previdência Social como uma diretriz política e social para questionar e debater possíveis propostas de reformas da Previdência Social que em breve serão colocadas em votação pelo atual governo. Assim, o objetivo geral desse trabalho é analisar o incrementalismo das políticas públicas de previdência social a partir da

\footnotetext{
${ }^{1}$ Universidade Federal de Viçosa
} 
Constituição Federal de 1988 e compreender o contexto da reforma proposta em 2016, discutida em 2017 e 2018.

Portanto, o presente estudo é pertinente face ao contexto de sucessivas reformas, dentre elas, a Emenda Constitucional n. 20 (1998), a Emenda Constitucional n. 41 (2003), a Emenda Constitucional n. 47 (2005), a Lei n. 12.618 (2012), a Lei n. 13.183 (2015). Além disso, se mostra contemporâneo por abordar o Projeto de Emenda Constitucional n. 287 (2016), contribuindo dessa forma, para as discussões acadêmicas e políticas sobre a formulação de políticas públicas no campo previdenciário, além de trazer elementos importantes às futuras propostas de reformas que serão trazidas pelo Presidente Jair Bolsonaro.

\section{FUNDAMENTOS TEÓRICOS}

\subsection{A formação da Previdência Social no Brasil}

No Brasil, as políticas de proteção social que contemplam a Seguridade Social visam resguardar a Saúde, a Assistência Social e a Previdência Social. A Seguridade Social surgiu com esse tripé (Saúde, Assistência e Previdência), após a Constituição Federal de 1988 (CF/88), que pelo seu caráter protetor tentou assegurar o máximo de direitos possíveis ao cidadão.

Dessa forma, a formação da seguridade social brasileira na qual está inserida a Previdência Social, segundo Silva (2014), pode ser dividida em cinco momentos distintos: 1923 a 1930, com a promulgação da Lei Eloy Chaves e a criação das Caixas de Aposentadorias e Pensões (CAPs); 1931 a 1945, com o aperfeiçoamento das CAPs com a criação dos Institutos de Aposentadorias e Pensões (IPAs); 1946 a 1963 , com o período de redemocratização do país; 1964 a 1985, com a reestruturação conservadora de 1986 a 2017, a promulgação da CF/88 e a implantação do Estado democrático de direito.

Convém destacar que durante essa trajetória de noventa e três (93) anos a Previdência Social no Brasil passou por inúmeras mudanças que ocorreram por meio das alterações legais, as quais concretizaram as políticas públicas de previdência no campo nacional, especialmente após a promulgação da Constituição Federal de 1988.

Dentre as alterações, se destacam: Emenda Constitucional n. 20 (1998), Emenda Constitucional n. 41 (2003), Emenda Constitucional n. 47 (2005), Lei n. 12.618 (2012), Lei n. 13.183 (2015) e o Projeto de Emenda Constitucional n. 287 (2016) ainda em trâmite. Leis oriundas de diferentes governos, segundo mandato do Presidente Fernando Henrique Cardoso, primeiro e segundo mandato de Luís Inácio Lula da Silva e segundo mandato de Dilma Rousseff, respectivamente.

Vale destacar que a Seguridade Social seria aquela responsável por proteger o indivíduo e a família contra as adversidades da vida, já Previdência Social como parte integrante da seguridade, seria aquela responsável por amparar o trabalhador das desventuras que poderiam afastá-lo do mercado de trabalho. Tornando assim, fundamental compreender o contexto no qual está inserido o surgimento da Previdência Social, da mesma forma que importa saber como se comporta o sistema previdenciário brasileiro, no intuito de analisar a formulação de políticas públicas no campo previdenciário por meio das principais mudanças legais desde a promulgação da Constituição Federal de 1988.

\subsection{A Formulação de políticas públicas sob a ótica do modelo de análise Incremental}

A Política Pública pode ser compreendida como uma diretriz formulada para o enfrentamento de um problema público. Trata do conteúdo concreto e simbólico de decisões políticas, do processo de construção e atuação dessas decisões (SECCHI, 2014). Para Mead (1995), é definida como um 
campo dentro do estudo da política que analisa o governo à luz de grandes questões públicas.

Para a análise da formulação de políticas públicas faz-se necessário a abordagem ao ciclo da política pública, conforme Howlett, Ramesh e Perl (2013), como seguinte processo sequencial: montagem da agenda; formulação da política; tomada de decisão implementação da política e avaliação da política.

A abordagem do ciclo como uma análise por fases do processo político, apesar das críticas ao modelo por ser considerado de caráter funcionalista e racional, é ainda muito útil por possibilitar a percepção de que existem diferentes momentos no processo de construção de uma política. A compreensão do ciclo político apenas demonstra e reforça a ideia de um "tipo ideal" para planejamento e tomada de decisão.

No entanto, a formulação da política é o momento no qual dentro do governo, se formulam soluções e alternativas para o problema e onde se expressa a relação de poder estabelecidos entre os aspectos sociais, políticos e econômicos. A definição entre alternativas representa uma escolha permeada de conflitos e esta decisão implica em alocar poder entre grupos com distintos interesses (SIDNEY, 2007).

Diante da complexidade do processo de formulação e tomada de decisão, a ciência política desenvolve e utiliza nas políticas públicas os modelos conceituais que visam, segundo Dye (2005), identificar aspectos importantes de questões político-sociais; auxiliar na comunicação direcionando esforços para compreender melhor as políticas públicas e prever as consequências dessas políticas.

Para tal, este autor traz os seguintes modelos: Modelo Institucional, Modelo de Processo, Modelo de Grupo, Modelo de Elite, Modelo Racional, Modelo Incremental; Modelo da Teoria dos Jogos; Modelo da Opção Pública, Modelo Sistêmico e Modelo Racional, dentre eles será aqui utilizado apenas o Modelo Incremental.

O Modelo Incremental, nasce nos Estado Unidos e tem a vertente de estudo do processo orçamental e apresenta um viés conservador, pouco compatível com as necessidades de mudanças. De acordo com Souza (2006), a visão da política pública como um processo incremental foi desenvolvida por Lindblom (1979) e Wildavisky (1992). Baseados em pesquisas empíricas, esses autores argumentaram que os recursos governamentais para um programa, órgão ou uma dada política pública não partem do zero e sim, de decisões marginais e incrementais que desconsideram mudanças políticas ou mudanças substantivas nos programas públicos.

Dye (2005), trata o Modelo Incremental como uma política baseada em variações sobre o passado, na qual a política pública é vista como uma continuação das atividades de governos anteriores com apenas algumas modificações marginais, sendo considerado conservador no sentido de que os atuais programas, políticas e despesas são utilizados como ponto de partida. A atenção é voltada para os acréscimos ou decréscimos dos programas já em vigor.

Os formuladores geralmente aceitam a legitimidade dos programas estabelecidos e concordam em dar continuidade, devido à falta de capacidade preditiva suficiente, a restrição de tempo, a restrição de informações sobre os custos, as incertezas quanto as consequências de mudanças mais radicais e principalmente por ser politicamente mais conveniente.

A opção pelo modelo Incremental decorreu da necessidade de compreender as sucessivas leis e reformas que ditam a política previdenciária brasileira. A Previdência Social, desde a promulgação da Constituição Federal de 1988, foi contemplada com a edição de inúmeras leis ordinárias, leis complementares, medidas provisórias e emendas constitucionais que variam de acordo com a situação econômica e política do país. Muitas dessas normas não são inovadoras e apresentam um viés incremental que será analisado mais adiante. Assim, as políticas passadas ditam e orientam a compreensão da reforma que está sendo discutida e votada desde o ano de 2016.

Observa-se a relevância dos estudos sobre os modelos de análise para então entender as 
características essenciais de uma política pública, bem como a relação dos formuladores de política com a sociedade e os reflexos econômicos, políticos e sociais. Nesse escopo, nenhum trabalho científico foi encontrado considerando o modelo incremental para análise da política de previdência social, o que evidencia uma verdadeira lacuna teórica. Já o modelo incremental e as políticas fiscais foram abordadas por Fittipaldi (2017) e Zugman (2016) e reforçam o incrementalismo nas políticas contemporâneas brasileiras.

\section{PROCEDIMENTOS METODOLÓGICOS}

O delineamento metodológico desse estudo é de natureza exploratória e se trata de uma pesquisa qualitativa predominantemente documental e bibliográfica, na qual abrange um conjunto de procedimentos a serem seguidos visando a qualidade e a confiabilidade da pesquisa.

A análise documental quanto um método exige técnicas de análise e de coleta dos dados. Em relação ao universo de análise, o estudo compreende as principais alterações legais como concretização de políticas públicas de previdência que ocorreram após a Constituição Federal de 1988, ou seja, dados primários que podem ser encontrados nos sites institucionais do Congresso Nacional e da Previdência Social. São eles: Emenda Constitucional n. 20 (1998), Emenda Constitucional n. 41 (2003), Emenda Constitucional n. 47 (2005), Lei n. 12.618 (2012), Lei n. 13.183 (2015) e o Projeto de Emenda Constitucional n. 287 (2016). Além da pesquisa documental com as distintas legislações foi realizada a pesquisa bibliográfica com dados secundários, artigos, livros e teses foram usadas para dar suporte à análise global do artigo.

$\mathrm{Na}$ análise documental dos dados foi utilizada a técnica de análise de conteúdo. Dentre as diferentes fases da análise de conteúdo, destacam-se 1) pré-análise, 2) exploração do material e 3) tratamento dos resultados (BARDIN, 2009).

$\mathrm{Na}$ primeira etapa foram selecionadas as principais legislações previdenciárias que tiveram relevância para o tema de formulação de políticas públicas consoante o modelo Incremental. Já na segunda etapa foi analisada as alterações, unindo os traços incrementalistas de cada norma e ao final explorou o material de forma interpretativa. Por fim, foram criadas categorias de análise extraídas dos trabalhos de Lindblom (1979), Wildavisky (1992), Dye (2005), Souza (2006) e Peters (1998).

Figura 1: Modelo conceitual de análise

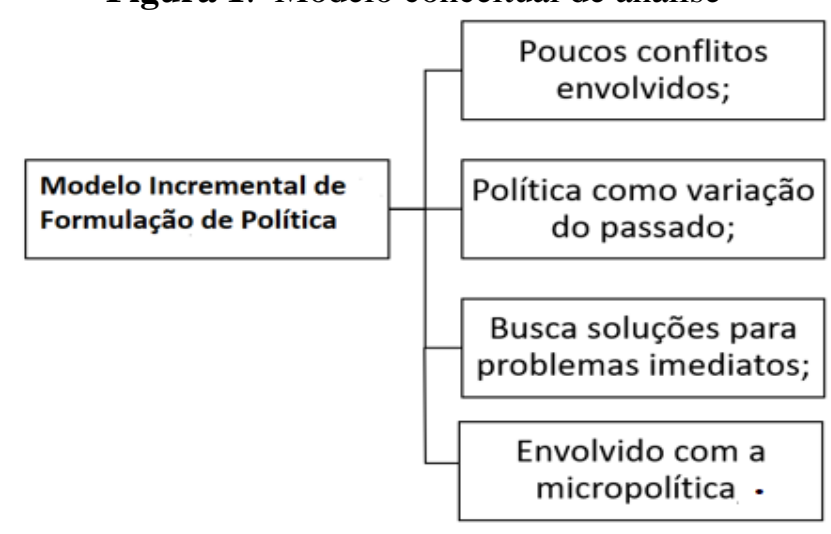

Fonte: Adaptado de Lindblom (1979), Wildavisky (1992), Dye (2005) e Peters (1998). 


\section{DISCUSSÃO E RESULTADO}

\subsection{A formulação de políticas públicas de previdência social após a promulgação da Constituição Federal de 1988}

A formulação de políticas públicas de previdência após a promulgação da Constituição Federal de 1988 será analisada conforme o modelo incremental de acordo a questão dos conflitos envolvidos, a sua realização como mera variação de políticas pretéritas, a busca por soluções imediatas e focada na micropolítica.

\section{Análise da Emenda Constitucional n. 20 (1998) - EC 20/1998}

Como fruto do processo de redemocratização, a Constituição Federal de 1988 representa um marco na história da previdência social brasileira, pois foi por meio do conceito de seguridade social, que ela evidenciou uma preocupação com a necessidade de garantir a todos os cidadãos os direitos sociais relativos à previdência, saúde e assistência. De acordo com Giambiagi e Além (2008), embora as mudanças estabelecidas pela nova Constituição tenham sido voltadas para a promoção do bem-estar de vários grupos marginalizados, a ampliação dos direitos dos beneficiários da previdência social ocorreu sem que houvesse o aumento da receita previdenciária para então manter o equilíbrio financeiro do sistema.

Neste contexto, os déficits previdenciários, tornaram-se prioridade na agenda política e econômica do Brasil no Governo de Fernando Henrique Cardoso e permanecem até hoje como um desafio aos governantes. Em 1995, a proposta de reforma da previdência foi enviada ao Congresso Nacional e somente em 1998 ocorreu a aprovação da EC 20/1998. Por meio de seus dezessete artigos a EC 20/1998 modificou o sistema de previdência social e estabeleceu normas de transição.

Dentre as alterações se destacam: a eliminação da aposentadoria proporcional para novos servidores público; estabelecimento de um período mínimo de contribuição; maior rigor para a obtenção de aposentadorias; alteração na forma de cálculo do benefício de aposentadoria com a introdução do Fator Previdenciário. No que diz respeito aos servidores públicos e militares, segundo Giambiagi e Além (2008), o governo não realizou mudanças para tentar conter o desequilíbrio financeiro, devido a fortes pressões políticas desse segmento.

A inserção do Fator Previdenciário, aprovado pela Lei n 9.876 de 1999, também representou um dos principais aspectos de mudanças trazidas pela EC 20/1998. Conforme Eduardo e Eduardo (2011), o Fator Previdenciário é um fator multiplicativo aplicado às Aposentadorias por Tempo de Contribuição que se baseia no tempo de contribuição, idade do trabalhador e expectativa de sobrevida, tem por finalidade desestimular aposentadorias precoces. Quanto menor a idade no momento da aposentadoria, menor será o benefício.

Existem, nessa emenda, fortes tendências ao modelo incremental, pois há uma nítida atuação da política como variação do passado, tentando fazer ajustes, especialmente econômicos, por meio da implantação do fator previdenciário. Um dos seus objetivos foi aumentar o grau da justiça atuarial do sistema, o que impactou nas arrecadações por meio das contribuições. Nesse sentido, ainda fica evidente a busca por solução de problemas imediatos, ou seja, o grande número de segurados que se aposentavam muito cedo e colaboravam para o crescimento do déficit previdenciário, evidentemente desequilibrando o sistema atuarial.

Dessa forma, o modelo incremental foi o que mais se aproximou da realidade da EC 20/1998, uma vez que se apresenta uma política conveniente para os atores envolvidos, já que também procurou evitar 
grandes conflitos. Os formuladores dessa política mantiveram grande preocupação com os aspectos econômicos na tentativa de um ajuste atuarial, deixando de lado aspectos fundamentais dos direitos sociais.

\section{Análise da Emenda Constitucional n. 41 (2003) - EC 41/2003}

A EC 41/2003 é composta de onze artigos, dentre os quais abrange especificamente os servidores públicos da União, reformula a EC 20/1998, com algumas, porém significativas alterações (regra de transição), o que já evidencia o seu traço incrementalista. Contudo, aqui começam sucessivas reformas dos servidores que despertam grande resistência e mobilização dessa classe.

Ela assegura o direito adquirido e prevê o abono de permanência; institui a contribuição dos inativos e pensionistas; limita o valor da aposentadoria ao máximo pago pelo regime geral do INSS; garante a integralidade e paridade dos proventos de aposentadoria para os servidores que ingressaram no serviço púbico até a sua promulgação; veicula norma de transição acerca do teto e subteto; proíbe a invocação de direito adquirido em relação a qualquer espécie remuneratória percebida na data da promulgação da Emenda, que exceda o teto ou subteto.

Nesse aspecto, observa-se a reforma da Previdência que se iniciou com a EC 20/98 se consolidou com EC 41/2003 abarcando importantes mudanças para os servidores públicos da União, reformulando de maneira geral os critérios de aposentadoria, pensões, benefícios, contribuições, o que foi considerado um marco legal para essa categoria de trabalhadores.

Já em relação aos modelos de análise na formulação de política pública constata-se que não há por parte do Congresso Nacional a preocupação com o máximo ganho social, tendo em vista o discurso de déficit previdenciário e a necessidade de mudanças para que a previdência continuasse a ser superavitária foram os argumentos sustentados de forma reiterada e que até hoje são contestados.

O modelo incremental se adequa em certos aspectos ao que foi feito pela EC 41/2003, visto que é uma política que perpetua uma política anterior, como observado, ela tentou reafirmar e consolidar aspectos legais da EC 20/1998. Nesse intuito, fazem abordagens específicas que têm impacto direto para os cidadãos envolvidos, a priori os servidores públicos.

Ainda segundo o modelo incremental, é observada a política como uma variação do passado, por apenas editar normas que complementam as anteriores, contudo não é considerada uma política com poucos conflitos, visto que encontrou grande resistência dos servidores públicos.

Já em relação à micropolítica, ela está presente por referir-se apenas aos aspectos da previdência social nacional, em especial a normatização dos regimes próprios dos servidores públicos. Fica evidente a busca por solução de problemas imediatos. Ela é considera uma das primeiras tentativas de equiparar a previdência dos servidores públicos ao regime geral, o que ocorre de forma gradual e toma maiores proporções com a PEC 287 de 2016.

\section{Análise da Emenda Constitucional n.47 (2005) - EC 47/2005}

A EC 47/2005 é mais uma breve reforma no sistema previdenciário brasileiro que trouxe pequenas mudanças perpetuando a política como variação do passado, mas ao mesmo tempo reforçando a política de inserção de trabalhadores considerados excluídos do Regime Geral de Previdência Social (RGPS). Essa pequena reforma ainda no governo Lula faz parte das sucessivas medidas legais que tentaram uniformizar a previdência dos servidores públicos com o regime geral.

Destaca-se o teto remuneratório e a aposentadoria estatutária no âmbito dos servidores públicos. Já em relação ao financiamento, ocorreu a expansão das contribuições sociais, e no RGPS a criação de critérios diferenciadores da aposentadoria dos deficientes físicos e a contribuição diferenciada do 
trabalho doméstico, no âmbito da própria casa, que comprove baixa renda.

Pode-se inferir que essa emenda apresenta traços incrementalistas quanto aos servidores públicos, o que já foi identificado nas emendas anteriores, as quais apresentaram uma série de mudanças em um curto período.

Inovações legais no regime geral incluem categorias de trabalhadores que estavam na informalidade, como os ambulantes, as donas de casa e outros trabalhadores de baixa renda, que nesse momento passaram a fazer parte do sistema previdenciário. A formalização foi um importante passo para a redução dos déficits previdenciários, bem como a ampliação das contribuições sociais.

Essas medidas podem ser consideradas uma busca por soluções imediatas, em especial para o déficit previdenciário, que a cada governo surgem iniciativas para tentar contê-lo reiterando, portanto, o caráter incrementalista da norma.

\section{Análise da Lei n. 12.618/2012}

A referida lei foi formulada no primeiro mandato da Presidente Dilma e instituiu e regime complementar para os servidores públicos federais eletivos. A promulgação dessa lei veio efetivar a previsão legal da EC 20/98 a qual já previa a criação da previdência complementar e corrobora as reformas anteriores dos governos Lula e Fernando Henrique Cardoso, os quais já tentavam uniformizar as normas dos servidores públicos ao regime geral.

Dessa maneira, os servidores públicos que ingressam na carreira a partir da promulgação dessa norma teriam que se filiar ao regime obrigatório, também conhecido como Regime Próprio de Previdência (RPPS) e poderiam fazer a escolha voluntariamente pelo regime de capitalização complementar (Funpresp).

A vantagem da previdência complementar trazida pela Lei 12.618/2012 ocorre no momento em que os servidores não poderiam mais se aposentar com o teto do serviço público, ou seja, o teto aplicável a essa categoria seria o regime geral (INSS), por meio da extinção da paridade e integralidade que ocorreu com a EC 41/2003. Os servidores que já faziam parte do regime obrigatório antes de 2012 também poderiam fazer a adesão a esse novo sistema complementar.

O texto legal ainda permite a criação das entidades de previdência complementar, o Funpresp para os poderes Legislativo, Executivo e Judiciário o que trouxe impactos nos níveis micro e macroeconômico, no que se refere primeiramente (micro) aos servidores e em segundo plano (macro) reflexos nas finanças públicas.

Embora essas medidas evidenciem características incrementais de política como variação do passado, ao corroborar as sucessivas reformas dos servidores públicos, essa lei não está apenas tentando solucionar problemas imediatos, visto que a previdência complementar é uma preocupação para o futuro. Da mesma forma, ela inovou no ordenamento jurídico criando novas instituições de previdência e o novo regime complementar, que até então não existia.

Os traços incrementalistas estão presentes em algumas passagens da norma, mas ao analisá-la na sua integralidade observa-se que ela não possui de forma preponderante o incrementalismo, apresentando inovações.

\section{Análise da Lei n. 13.183/2015}

A Lei $n^{\circ}$ 13.183/2015 trata da alteração da Aposentadoria por Tempo de Contribuição - ATC com a implantação da Regra 85/95 Progressiva, como medida alternativa ao Fator Previdenciário. A atual Regra da ATC traz ao beneficiário a possibilidade de escolha, proporcionando-lhe a condição de receber a aposentadoria integral, sem aplicação do Fator Previdenciário. 
Conforme Goes (2015), para a não aplicação do Fator Previdenciário e a obtenção do benefício da ATC integral, o beneficiário poderá optar pela Regra 85/95, que exige pelo menos 30 anos de contribuição para as mulheres e 35 para homens, sendo necessário somar a idade ao tempo de contribuição, inicialmente de 85 pontos para as mulheres e 95 pontos os para homens. A atual regra é progressiva e sofrerá o acréscimo de um ponto a cada dois anos a partir de dezembro de 2018 até dezembro de 2026, quando a soma para as mulheres passará a ser de 90 pontos e para os homens de 100 pontos.

Diante deste cenário geral, cumpre destacar que sob a vertente do modelo incremental se destaca a falta de grandes conflitos para a implantação da Regra, tendo em vista que o discurso do governo foi focado apenas no curto prazo, período de perceptível vantagem. Outro aspecto também de relevância é que essa política representa apenas uma variação da política já existente, trazendo somente abordagens marginais e, mais uma vez, a tentativa de solucionar problemas imediatos relacionados aos critérios de aposentaria, tentando modificar as formas de concessão para reduzir o déficit previdenciário.

Nestes aspectos, o modelo incremental é o que mais se adequa, uma vez que apresenta uma política com viés conservador, com decisões fáceis e sem profundas mudanças, se apresentando politicamente conveniente por dar continuidade à políticas e programas já existentes.

\section{Análise do Projeto de Emenda à Constituição n. 287 (2016) - EC 287/2016.}

Já o Projeto da EC 287/2016 e o substitutivo apresentado pelo relator em 19.04.2017 propõe a alteração dos artigos 37, 40, 109, 167, 195 e 201 da Constituição Federal, ou seja, muda em grande parte os benefícios, por meio da unificação ou diminuição dos critérios diferenciadores das aposentadorias entre homens e mulheres; por estipular uma idade mínima para se aposentar; por proibir a acumulação de pensão por morte; extinguir aposentadoria especial, estipular contribuição para os trabalhadores rurais e por criar regra de transição para quem não tem condições de aposentar no momento da transição legal, dentre outros.

Essa reforma segue a linha do processo reformista dos anos 1990. Em 2016, o atual Presidente da República Michel Temer tenta implementar políticas de austeridade fiscal e gerar confiança do mercado financeiro usando os mesmos argumentos de outras reformas pretéritas de déficit crescente do fundo previdenciário, que inviabilizaria a perpetuação do sistema da seguridade social. Outros argumentos são trazidos, como o envelhecimento da população e a mudança da pirâmide etária brasileira, o que culmina na necessidade de uma idade mínima para se aposentar. Distintas alterações propostas, ainda dizem respeito à redução dos critérios diferenciados de aposentadoria dos servidores públicos e a isonomia entre os diferentes regimes previdenciários.

Assim esta reforma, que tem passado por mudanças, contempla apenas alterações nos benefícios previdenciários, sendo um deles a extinção da aposentadoria por tempo de contribuição, com a definição de uma idade mínima para se aposentar. No entanto, não abrange nenhuma alteração nas bases de Custeios da Previdência e não aponta qualquer aumento da fiscalização para evitar concessões de benefícios imprecisamente. Da mesma forma que não aborda a negociação de dívidas com os devedores, no qual centenas de médias e grandes organizações possuem dívidas previdenciárias vultosas e de notório conhecimento público.

Nestes aspectos, observa-se uma política pública de caráter reestruturante, por promover vastas alterações. Por essa vertente, essa atual proposta não tem um viés conservador, assim, não se aproxima exaustivamente do modelo incremental, como as emendas constitucionais analisadas, uma vez que as possíveis alterações legais irão mudar o panorama previdenciário completamente.

Afinal, a PEC 287/2016 também não visa apenas a solução para os problemas imediatos da previdência social, a reforma é realizada a longo prazo e prevê no seu bojo sucessivas reformas de acordo 
com a mudança da expectativa de vida do brasileiro, ou seja, já indica que futuras reformas são vitais para a manutenção do equilíbrio financeiro e atuarial.

\section{CONSIDERAÇÕES FINAIS}

Essa pesquisa se propôs a analisar a formulação das principais políticas públicas da previdência social após 1988 de acordo com as alterações legais de maior mudança social e econômica. Para alcançar esse propósito foi discutida a formação da Seguridade Social e da Previdência Social para então abordar o modelo incremental de formulação de Políticas Públicas. A análise realizada evidenciou a aproximação ao modelo incremental, por meio de políticas superficiais no âmbito previdenciário que historicamente se preocuparam em tentar sanar dificuldades de cunho financeiro e atuarial, pouco se debruçando sobre as questões sociais.

Diante da análise das legislações previdenciárias, verifica-se que a EC 20/1998, EC 41/2003, EC 47/2005 e a Lei 13.183/2015 tiveram caráter predominantemente incremental, que afetaram os servidores públicos e tentaram acompanhar a transição demográfica da população no intuito de equilibrar as contas previdenciárias. Já as Lei 12.618/2005 e a PEC 287/2016 trouxeram propostas mais inovadoras buscando novamente a manutenção das condições de solvência e sustentabilidade do sistema previdenciário no longo prazo.

É possível perceber a relevância da política pública de Previdência Social, a qual demandou inúmeras reformas. Porém, observa-se a necessidade de reformas que realmente tenham relevância para sanar os possíveis desequilíbrios, equalizando os ganhos e custos entre as gerações, proporcionando o aumento da capacidade de crescimento da economia e o aumento do bem-estar social. Infere-se que as sucessivas reformas colaboram para a morosidade e burocratização do sistema o que gera a judicialização e o aumento das despesas públicas.

Esse artigo contribui para o entendimento da efetividade da política pública previdenciária, quanto à redução das desigualdades sociais e o equilíbrio do sistema previdenciário, diante do atual cenário socioeconômico brasileiro, ajudando-nos a manter conscientes e atentos quanto aos nossos direitos, inclusive de cidadania.

Em outro aspecto, ainda há limitações nesse estudo, dado que a PEC 287/2016 sofreu mudanças com o novo governo eleito em 2018, o que torna mais complexa a análise do modelo incremental. Entretanto, já está sinalizado que novos estudos enfatizando os modelos de formulação de políticas são de extrema importância para o mundo acadêmico que carece de pesquisas que ajudem a compreender as demandas sociais atuais.

\section{REFERÊNCIAS}

BARDIN, L. Análise de Conteúdo. Lisboa: Edições 70, 2009.

BOSCHETTI, I. Seguridade social no Brasil: conquistas e limites à sua efetivação. CFESS. Conselho

Federal de Serviço Social. (Org.). Serviço Social: direitos sociais e competências profissionais. Brasília: CEAD/Ed. UnB, 2009.

BRASIL, Lei $\mathbf{n}^{\mathbf{0}}$ 13.183, de 14 de novembro de 2015. Disponível em: <http://www.planalto.gov.br/ccivil_03/_Ato2015-2018/2015/Lei/L13183.htm>. Acesso em 10 nov. 2017. 
BRASIL, Lei $\mathbf{n}^{\mathbf{0}}$ 9.876, de 26 de novembro de 1999. Disponível em:

<http://www.planalto.gov.br/ccivil_03/leis/L9876.htm>. Acesso em 10 nov.2017.

BRASIL. Constituição Federal de 1988. Disponível em:

$<$ http://www.planalto.gov.br/ccivil_03/constituicao/constituicaocompilado.htm> Acesso em 29 nov. 2017.

BRASIL. Projeto de Emenda à Constituição, $\mathbf{n}^{\circ} 287$ de 2016. Disponível em:

$<$ http://www.camara.gov.br/proposicoesWeb/prop mostrarintegra;jsessionid=0EF6691E6AA30A8F8446B7B

47DA870E3.proposicoesWebExterno1? codteor $=1514975 \&$ filename $=\mathrm{PEC}+287 / 2016 \mathrm{\gamma}$. Acesso em 06 nov. 2017.

CUNHA, E. D. P.; CUNHA, E. S. M. Políticas Públicas Sociais. In: CARVALHO, A., DAHL, R. A. On democracy. New Haven: Yale University Press, 2000.

DYE, T. R. Models of politics; some help thinking about public policy. In: Understanding public policy. 11. ed. New Jersey. Prentice-Hall, 2005. p.11-30.

EDUARDO, I. R.; EDUARDO, J. T. A.. Direito Previdenciário-Benefícios. 3 ed. Rio de Janeiro: Elsevier, 2011. 328 p.

FITTIPALDI, I.; COSTA, S. F.; ARAÚJO, C. M. C. O Gasto Público Federal Brasileiro: Um Perfil Incrementalista? Revista do Serviço Público, v. 68, n. 3, p. 611-630, 2017.

GIAMBIAGI, F.; ALÉM, A.C. Finanças Públicas: teoria e prática. 3. ed. Rio de Janeiro: Elsevier, 2008.

GOES, H. M. Manual de Direito Previdenciário: teoria e questões. 10. ed. Rio de Janeiro: Ferreira, 2015. $864 \mathrm{p}$.

HeIDEMANN, F. G.; SALM, J. F. Org. Políticas Públicas e desenvolvimento: bases epistemológicas e modelos de análise. 3. ed. Brasília: Editora Universidade de Brasília, 2014.

HOWLETT, M.; RAMESH, M.; PERL, A. Política Pública: seus ciclos e subsistemas - uma abordagem integradora. Rio de Janeiro: Elsevier, 2013.

JANN, W.; WEGRICH, K. The Teories of the policy cycle. In: FISHER, F.; MILLER, G. J.; SIDNEY, M. S. Handbook of policy analysis: theory, and methods. [S.1.]: CRC Press, 2007.

LINDBLOM, Charles E. Still Muddling, Not Yet Through, Public Administation Review, v. 39, p. 517$526,1979$.

LOWI, T. American Business, Public Policy, Case Studies and Political Theory. World Politics, v 16, n 4, p. 677- 715, jul.1964.

MATIAS-PEREIRA, J. Gestão Pública, Governabilidade, Governança e Accountability Parte I. In: MATIAS-PEREIRA, J. Manual de Gestão Pública Contemporânea. 7. ed. São Paulo: Atlas, 2008.

MEAD, L. M. Public Policy: Vision, Potential, Limits. Policy Currents, n.1-4, fev. 1995.

MOZZATO, A. R.; GRZYBOVSKI, D. Análise de conteúdo como técnica de análise de dados qualitativos no campo da Administração: potencial e desafios. Revista de Administração Contemporânea, v. 15, n. 4, p. 731-747, 2011.

RUA, M. D. G. Políticas Públicas. Departamento de Ciências da Administração/UFSC. Florianópolis, p. 130. 2009.

SECCHI, L. Políticas Públicas: Conceitos, esquemas de análises, casos práticos. 2 ed. São Paulo: Cengage Learning, 2014. 
SILVA, L.L. Formação do Sistema Previdenciário Brasileiro: Fatores Históricos e Econômicos. 2014. 175 f. Dissertação (Mestrado em Administração) - Universidade Federal de Viçosa, Viçosa, 2014. Disponível em: http://www.locus.ufv.br/handle/123456789/1989. Acesso em: 10 out. 2017.

SIDNEY, M. S. Policy Formulation: Design and Tools. In: FISCHER, F.; MILLER, G.J.; SIDNEY, M. S. Handbook of Public Policy Analysis. New York: CRC Press, 2007. cap. 6.

SOUZA, C. Políticas Públicas: uma revisão da literatura. Sociologias, Porto Alegre, v. 8, n. 16, p. 20-45, jul/dez. 2006.

TRIVINOS, A. Introdução à pesquisa em ciências sociais: a pesquisa qualitativa em educação. São Paulo: Atlas, 1987.

WILDAVSKY, A. The Policy of Budgetary Process. 2.ed. Boston: Little and Brown, 1992.

ZANIRATO, S. H. O descanso do guerreiro: um estudo sobre a instituição da previdência social no Brasil. Maringá: Eduem, 2003.

ZUGMAN, D. L. Reflexões sobre as possíveis razões para não ocorrer uma reforma tributária no Brasil. Revista Direito FGV, v. 12, n. 3, p. 610-631, 2016. 